\title{
REPRESENTAÇÕES SOCIAIS DOS ALUNOS SOBRE PESQUISA COMO PRINCÍPIO EDUCATIVO
}

\author{
Felipe Fabri Silveira ${ }^{1}$ \\ Antonio Serafim Pereira ${ }^{2}$
}

\section{Resumo}

O presente trabalho resultante do projeto PIBIC/UNESC, analisou as representações sociais dos alunos do colégio de uma universidade do sul catarinense sobre pesquisa escolar. Para a análise dos dados, tomamos os seguintes autores como referência: Moscovici (2000), Demo (1990, 1994, 2007), Beillerot (2001), entre outros. Inicialmente procedemos a análise documental do projeto político pedagógico do colégio em questão no que se refere à pesquisa escolar. As representações sociais dos alunos (Ensino Fundamental, 8o e 9o anos) foram coletadas por meio de entrevistas. Além disso, nos valemos de questionário sobre suas vivências escolares em relação à pesquisa, visando ampliar e aprofundar os dados coletados anteriormente. Do processo analítico empreendido, algumas questões, que a literatura vem apontando, entre elas, a internet/livro didático como fonte de coleta de dados e atribuição de nota como objetivo precípuo da pesquisa em detrimento do aprender a pesquisar, foram confirmadas. As representações sociais dos alunos, no entanto, nos possibilitaram captar possibilidades significativas em relação às experiências a eles oportunizadas no campo da pesquisa como: o aprofundamento crítico relativo aos temas estudados, a oportunidade oferecida pela pesquisa de relacionar os conteúdos das disciplinas com a realidade social, incluindo a experiência da elaboração de texto de forma mais autoral.

Palavras - chave: Representações sociais; Pesquisa; Alunos; Ensino Fundamental.

\section{SOCIAL REPRESENTATION OF STUDENTS ABOUT RESARCH AS EDUCATIONAL PRINCIPLE}

\begin{abstract}
The following work, resulting from the PIBIC / UNESC project, analyzed the social representations of the students of the college of a university in southern of Santa Catarina on school research. For the analysis of the data, we take the following authors as reference: Moscovici (2000), Demo (1990, 1994, 2007), Beillerot (2001), among others. Initially we proceeded the documentary analysis of the political pedagogical project of the college in question, with regard to the school research. The social representations of the students (Elementary School, 8th and 9th grade) were collected through interviews. In addition, we use a questionnaire about their school experiences in relation to research, seeking to broaden and deepen the data collected previously. From the analytical process, some questions, which the literature has been pointing out, among them, the internet / didactic book as a source of data

\footnotetext{
${ }^{1}$ Acadêmico do curso de Pedagogia/ bolsista PIBIC/UNESC, R. Raimundo Coelho de Campos, 740, Santa Catarina, Araranguá/SC, 88902-554, felipefabri201@unesc.net.

2 Docente pesquisador PPGE/FORGERSB/UNESC, R. Maestro Antônio João Ramos, 200/1001, Predial, Torres/RS, 95560-000, asp@unesc.net.
}

Criar Educação, Criciúma, v. 7, no2, jul/dez 2018.- PPGE - UNESC
\end{abstract}


collection and attribution of note as the primary objective of the research rather than learning to research, have been confirmed. The social representations of the students, however, enabled us to capture significant possibilities in relation to the experiences offered to them in the field of research such as: the critical deepening of the subjects studied, the opportunity offered by the research to relate the contents of the disciplines to the social reality , including the experience of writing more authorally.

Keywords: Social representations; Research; Students; Elementary School.

\section{Introdução}

A pesquisa descrita neste trabalho é resultante do projeto PIBIC/UNESC, que analisou as representações sociais dos alunos do colégio de uma universidade do sul catarinense sobre pesquisa enquanto princípio educativo.

Os dados foram coletados, inicialmente, com $39^{3}$ alunos dos anos finais do Ensino Fundamental ( $8^{\circ}$ e 9o anos) selecionados aleatoriamente ${ }^{4}$, por meio de entrevistas semiestruturadas acerca das suas representações sociais sobre pesquisa escolar. Na sequência, os textos das entrevistas transcritas foram apresentados aos alunos para validação das informações neles contidas. Além disso, nos valemos de questionário (Escala Likert) sobre suas vivências escolares em relação à pesquisa, visando ampliar e aprofundar os dados.

Cabe salientar, que anteriormente aos procedimentos metodológicos mencionados, desenvolvemos a análise documental do projeto político pedagógico (PPP) do colégio, em vigência a partir de 2016, buscando identificar como a pesquisa, enquanto estratégia de ensino nele se expressa. As informações contidas no PPP e nas entrevistas realizadas com os alunos, foram submetidas à análise de conteúdo (BARDIN, 2014), interpretadas à luz de Demo (1990, 1994, 2007), Castoriadis (1999), Moscovici (2000), Jodelet (2001), Beillerot (2001), Oliveira e Campello (2016), entre outros autores.

\section{Representações sociais: aportes teóricos}

Representações sociais são juízos de valor compartilhados nas relações sociais, que se constituem em conversas informais na escola, em família, grupos de

\footnotetext{
${ }^{3}$ Correspondente a $46 \%$ dos alunos dos anos considerados.

4 Participação por adesão voluntária

Criar Educação, Criciúma, v. 7, no2, jul/dez 2018.- PPGE - UNESC
} 
amigos e nos diversos grupos de convivência dos quais as pessoas participam. Significa dizer que as representações "não são criadas por um indivíduo isoladamente". (MOSCOVICI, 2000, p. 40). Na mesma direção, Jodelet (2001) afirma que as representações sociais se referem ao sentido que as pessoas em conjunto atribuem a um determinado fenômeno. Enquanto sistemas de interpretação, que fundamentam suas relações com o mundo e com os outros, as representações sociais direcionam o pensamento e o comportamento das pessoas. Vale salientar, que o sentido, segundo Castoriadis (1999), é criado pela sociedade não somente em relação ao significado que as coisas têm para ela. Conforme o autor, " não há sentido que nos seja dado de presente" [...], só há sentido quando criamos na e pela história. (CASTORIADIS, 1999, p. 21).

Representações sociais podem ser comparadas com o conhecimento empírico, em vista do compartilhamento que as pessoas realizam, porém, Moscovici (2000), apresenta dois critérios básicos que a legitimam: convenção e prescrição.

Primeiro, as representações sociais convencionalizam os objetos, pessoas, ou acontecimentos, ou seja, as representações dão uma forma definitiva, categorizam e estabelecem modelos que passam a ser partilhados por um determinado grupo de pessoas. É por esse processo de convenção que

passamos a afirmar que a terra é redonda, associamos comunismo com a cor
vermelha, inflação com o decréscimo do valor do dinheiro. Mesmo quando
uma pessoa ou objeto não se adequam exatamente ao modelo, nós o
forçamos a assumir determinada forma, entrar em determinada categoria, na
realidade, a se tornar idêntico aos outros, sob pena de não ser nem
compreendido, nem decodificado. (MOSCOVICl, 2000, p. 34)

Segundo, as representações sociais são prescritivas, isto é, determinam o que deve ser pensado, exercendo sobre nós uma espécie de coerção/força. Segundo Moscovici, (2000, p. 37), as representações que possuímos sobre determinado assunto, não estão diretamente ligadas com a nossa maneira de pensar, mas as representações são impostas a nós de forma normativa e dependem das mudanças que ocorrem durante as gerações.

$\mathrm{Na}$ verdade, as representações sociais nos permitem nomear as diferentes experiências, fatos ou coisas que fazem parte da realidade vivenciada, uma vez que, conforme Guareschi (2000, p. 35), "são modos de conhecimento que surgem e legitimam-se na conversação interpessoal cotidiana e tem como objetivo compreender 
e controlar a realidade social". No caso deste trabalho, nos interessam as representações sociais dos alunos sobre pesquisa escolar, razão pela qual passamos a considerá-la no tópico a seguir.

\section{Pesquisa escolar: princípio educativo}

Entendemos por pesquisa enquanto princípio educativo a que se realiza no âmbito do contexto escolar, sem, contudo, desconsiderar que a pesquisa é exercida em muitos contextos como forma de encontrar um objeto, informação ou conhecimento, tendo em vista que, na vida cotidiana nos deparamos com diversas situações, que nos desafiam e exigem pensamento, questionamento/descoberta, alternativas de solução e tomada de decisão para enfrentá-las. (DEMO, 1990; BEILLEROT, 2001).

Beillerot (2001), no entanto, adverte que nem toda descoberta poderá ser considerada como pesquisa; o que encontramos por acaso ou intuição não pode ser nomeado como pesquisa. Segundo o autor, para que um trabalho se constitua como pesquisa deve atender a três critérios básicos, a saber: produção de conhecimentos novos, produção rigorosa de encaminhamento, comunicação de resultado.

A produção de um conhecimento novo corresponde à garantia de que o exercício da pesquisa produza uma compreensão ampliada e aprofundada do objeto em estudo que, segundo Demo $(1994,2007)$, se atinge a partir do que se denomina questionamento reconstrutivo. $O$ conhecimento que deve nos interessar em relação à pesquisa é o que se engaja no processo de interrogação; que questiona os sentidos estabelecidos e subverte as significações e verdades sociais aceitas. (CASTORIADIS, 1999).

O segundo critério refere-se ao processo metodológico suficientemente sistematizado na "investigação dos fatos, dos fenômenos e das ideias" (BEILLEROT, 2001, p.55,). O que, segundo Demo (1994), permitirá ao pesquisador intervir e dialogar de maneira competente $\mathrm{na} / \mathrm{com}$ a realidade.

Por último, o critério da comunicação dos resultados, diz respeito à socialização e discussão das apreensões e interpretações desenvolvidas na pesquisa com os principais interessados e/ou envolvidos no processo investigativo. Essa é a condição 
que nos permite a pesquisa, tendo em vista, que a partir dela se pode, como afirma Demo (1990), sair da condição de informado, para a condição de informante. Segundo o autor, quem produz conhecimento comunica, quem reproduz escuta. Tal condição remete à reflexão sobre o que o autor define como interpretação e elaboração própria por parte de quem pesquisa. O que tem a ver com o exercício da autonomia e, por extensão, ao processo de emancipação que, para o autor, corresponde ao "processo histórico de conquista e exercício da qualidade de ator consciente e produtivo. Tratase da formação do sujeito capaz de se definir e de ocupar espaço próprio, recusando ser reduzido a objeto". (DEMO, 1990, p. 78).

A par disso, os trabalhos publicados no período de 1989 a 2011 sobre pesquisa escolar, analisados por Oliveira; Campello (2016), no entanto, identificaram a predominância da prática da cópia e a falta de questionamento, contrariando assim, o que defendem as autoras ao situarem que o questionamento crítico e criativo é constituinte essencial da pesquisa. A cópia além de ferir este princípio, caminha no sentido contrário à emancipação; ressalta, pois, a condição de dependência do pesquisador em relação ao conhecimento produzido. Importa salientar, que os trabalhos investigados pelas autoras mencionadas ainda apontam como problemas relacionados à prática da pesquisa escolar, a falta de motivação dos alunos para a pesquisa, falta/precariedade de orientação dos professores, entre outros.

\section{Pesquisa escolar: a expressão do projeto político pedagógico, das entrevistas e questionários}

Neste segmento descrevemos a análise dos dados que emergiram do projeto político pedagógico (PPP) do colégio pesquisado ${ }^{5}$, dos dados das entrevistas e questionários com os alunos.

No projeto político pedagógico, a partir da análise documental, buscamos identificar como a categoria pesquisa se expressa (sentido e procedimentos); com os alunos dos anos finais do Ensino Fundamental ( $8^{\circ}$ e 9ํanos), por meio de entrevistas semiestruturadas, buscamos apreender suas representações sociais sobre pesquisa escolar, tendo como foco os seguintes aspectos: tipo de pesquisa realizada,

${ }^{5}$ Atende alunos do Ensino Fundamental e Médio

Criar Educação, Criciúma, v. 7, no2, jul/dez 2018.- PPGE - UNESC 
frequência, orientação dos professores, destino dos resultados e opinião dos alunos sobre suas experiências com a pesquisa. O conteúdo das entrevistas, foram apresentados aos alunos para validação, seguida da aplicação do questionário tipo Likert com o objetivo de ampliar e aprofundar os dados nelas contidos.

O projeto político pedagógico nos permitiu apreender a pesquisa como um dos princípios de ensino do colégio, ao afirmar seu compromisso com "o processo de apropriação e reconstrução do conhecimento" e "a pesquisa" como uma de suas prioridades, "visando à aquisição de conhecimentos significativos". (PPP, 2016, p. 3).

Tal compromisso, aparece fortalecido na indicação das atividades curriculares, ao situar a pesquisa como um dos recursos metodológicos a serem utilizados, junto a palestras, conferências, exposições, debates, seminários, intercâmbios, etc. (PPP, 2016).

Além disso, a indicação de que "o colégio, busca valorizar os conhecimentos elaborados a partir das relações que se estabelecem no meio extraescolar" (PPP, 2016, p. 16) e que "a metodologia de ensino [...] tem como objetivo o desenvolvimento da produção intelectual", com vistas a desenvolver a "análise crítica nas diferentes áreas do conhecimento". (PPP, 2016, p.18) nos levam a inferir qual o sentido implícito de pesquisa escolar que o colégio intenciona desenvolver: uma pesquisa que, a nosso ver, atende aos dois elementos básicos apontados por Demo (1994, 2007): questionamento reconstrutivo e elaboração própria.

A par dessas inferências, reputamos de bom alvitre interrogar: as considerações sobre pesquisa no PPP, ainda estão sob a influência do Ensino por Problematização e Pesquisa (EPP), proposta pedagógica elaborada/implementada coletivamente pelos profissionais da educação do colégio investigado (no período de 2003 a 2013)? Sim, porque tal proposta já considerava a pesquisa como estratégia fundamental para que o aluno exercesse sobre os conhecimentos, historicamente produzidos, elaboração própria, pensada e trabalhada criticamente, além disso, tendo como questão central do ensino não fazer pesquisa, mas aprender a pesquisar, a proposta realçava a importância do professor como orientador desse processo, acompanhando o estudo teórico, a análise dos dados e as produções dos alunos, até porque, se partia do princípio de que, por seu caráter pessoal, a pesquisa não denotaria simples tarefa a 
ser cumprida, nem se restringiria ao simples ato de entrega e mera avaliação e atribuição de nota pelo professor. (CARDOSO; PEREIRA, 2010)

Apresentados e descritos os dados referentes à pesquisa expressa no PPP, passamos, então, à descrição/interpretação dos dados oriundos das entrevistas com os alunos. Antes, porém, considerando os temas constantes do roteiro do procedimento em questão, indicamos as categorias de análise consideradas: tipo de pesquisa realizada, orientação dos professores, destino da pesquisa e opinião dos alunos sobre os trabalhos de pesquisa.

Quanto ao tipo de pesquisa, a maioria dos alunos indicou como fonte de coleta de dados a internet e a apostila adotada no colégio, como se pode evidenciar na fala da aluna do 9 ano: "na internet, nos livros. A gente usa bem, bastante os livros didáticos, apostila". Vale sublinhar, que a internet como recurso tecnológico para busca de dados, aparece com destaque nas produções analisadas por Oliveira e Campello (2016), que chamam a atenção para o fato de que este recurso pode facilitar a prática da cópia, mas, contraditoriamente pode incentivar a motivação dos alunos, "curiosidade, autonomia e criatividade, além de evitar a dispersão na coleta de informações e facilitar a comunicação professor/aluno". (Oliveira e Campello, 2016, p. 191). Resta saber, como se dá o uso da internet como dispositivo de pesquisa no colégio pesquisado, uma vez que, no contexto da pesquisa desenvolvida não obtivemos dados que nos permitam tecer considerações específicas a este respeito.

Os alunos também se referiram ao resumo sobre o conteúdo das disciplinas como uma das formas de pesquisa, como segue: "às vezes, alguns professores mandam a gente fazer algum resumo sobre o conteúdo" (Aluno do $8^{\circ}$ ano). Considerando que o resumo foi indicado pelos alunos como forma de facilitar o estudo, sem menção à sua utilização para compor a fundamentação teórica da análise de um tema ou situação específica, acreditamos que, a inclusão deste gênero textual pelos alunos, como modalidade de pesquisa, faz parte de um dos equívocos presentes nas representações dos alunos sobre pesquisa, ainda muito presente de modo geral no meio escolar.

Com menos indicação, os alunos destacaram também a pesquisa com colegas mediante o uso de questionário, expresso no depoimento da Aluna do 9ªno: "uma das pesquisas foi com o colégio todo, que a gente mostrou para todo mundo, para 
cada sala, qual foi o resultado da pesquisa, porque era tipo um questionário". Reafirmado pelo que diz a Aluna do 9ano: "a gente pesquisou sobre o que os alunos gostavam, sobre esporte, filme, que eles faziam no dia a dia."

Os alunos, em sua maioria, também mencionaram a orientação do professor na realização do trabalho de pesquisa, como revela um dos alunos ( $8^{\circ}$ ano): "orientam muito". Ou como destaca a Aluna do 8 ano: "o que fazer, como fazer, aonde pesquisar". Considerações reafirmadas pela Aluna do $9^{\circ}$ ano de que, em "todos os trabalhos, os professores geralmente tiram parte da aula para explicar sobre o trabalho; se tu tens dúvida eles explicam de novo, é bem explicado sobre os trabalhos que se tem que fazer". Este fato se contrapõe aos achados de Oliveira e Campello, (2016), posto que os trabalhos por elas analisados denunciaram a falta e/ou precariedade de orientação dos professores no que se refere aos trabalhos de pesquisa propostos aos alunos.

No que diz respeito, ao destino dos resultados da pesquisa, os estudantes pesquisados, em sua maioria, mencionaram que os trabalhos são apresentados em versão impressa e/ou de forma expositiva em aula, com o intuito de avaliação por parte do professor. Nesse sentido, assim se declara a Aluna do 8 ano "se faz trabalho de slide, apresenta para a sala ou trabalhos impressos, que a gente faz em casa e entrega na aula". Ou como relata a Aluna do 8ำ ano destacando o caráter avaliativo do trabalho de pesquisa: "normalmente se apresenta numa folha que o professor avalia depois, mas tem que colocar o trabalho em Power point".

Das opiniões dos alunos sobre a pesquisa que desenvolvem no colégio, colhemos desde a representação de que este procedimento metodológico contribui para a melhor compreensão e aprofundamento dos conhecimentos (5), oportuniza maior diálogo entre as pessoas (3), possibilita visões diferentes sobre o assunto estudado (2), constitui atividade diferente da aula (1), à ideia genérica de que a pesquisa é positiva (3).

Embora se possa questionar se tais considerações constituem representações sociais dos alunos pelo índice pouco expressivo das suas indicações, é significativa a opinião de uma Aluna do 9º ano sobre a contribuição para melhor compreensão e aprofundamento dos conhecimentos, a saber: "é bem interessante, porque se pode aprofundar mais no assunto e procurar outras formas de ver e obter mais 
informações". Quanto à oportunidade de diálogo entre os alunos, é representativa também a posição de uma das Alunas do $8^{\circ}$ ano, que assim se pronuncia: "eu acho muito bom, porque o trabalho aproxima a gente com outros colegas, oportunizando aprender mais sobre o trabalho [...]; não se fica tão focado na aula; aquela coisa muito chata, de sempre". Do mesmo modo, também é significativa a opinião de um dos Alunos do $9^{\circ}$ ano, sobre a possibilidade de ter visões diferentes sobre o tema alvo da pesquisa, como segue: "eu acho legal, interessante porque é um pouco diferente [...]; se diferencia um pouco da aula, do material que se usa normalmente. É uma forma diferente de pesquisar e ter visões diferentes sobre o assunto.

A positividade da pesquisa expressa pelos alunos do colégio em apreço, se contrapõe à falta de motivação para a pesquisa em destaque nas produções analisadas por Oliveira e Campello (2016), atribuída à não preocupação dos professores em selecionar temas contextualizados à vivência dos discentes, além da orientação precária daqueles, em relação à pesquisa a ser realizada. No caso específico do colégio investigado, a positividade da pesquisa apontada pelos alunos pode ser atribuída à presença dos fatores acima apontados como ausentes nos trabalhos analisados pelas referidas autoras?

Descrita a análise e interpretação das entrevistas, apresentamos na sequência o resultado dos questionários aplicados aos estudantes que participaram da pesquisa.

Segundo os alunos, a partir das questões estimuladas, característica da escala Likert, a coleta dos dados é feita na internet (91\%), seguida de livros e apostilas (51\%), índices reforçados por $57 \%$ dos alunos de que, a pesquisa com pessoas, buscando relacionar suas falas com os conhecimentos das disciplinas é, de certa forma, ausente. A totalidade dos alunos que responderam ao questionário indicaram que os trabalhos de pesquisa são entregues ao professor com o objetivo de atribuir nota (100\%), seguido de exposição como requisito para avaliação dos alunos que elaboraram o trabalho (51\%).

É importante enfatizar, que 78\% dos alunos apontaram que a apresentação da pesquisa, a partir das discussões com colegas e professores, resulta no aprofundamento crítico do tema abordado, na leitura crítica (67\%) e no questionamento (dúvida) sobre os conteúdos das disciplinas (45\%). Além disso, dá reforço a essa indicação o fato de os alunos (54\%) considerarem que os trabalhos de 
pesquisa ajudam a relacionar os conteúdos das disciplinas com a realidade social (contextualização). As indicações acima, podem se justificar de certa maneira, visto que, $69 \%$ dos alunos confirmaram que não escrevem no trabalho de pesquisa da mesma forma apresentadas nos textos ou materiais consultados. Considerando estes dados e a consideração de $72 \%$ dos alunos que os temas não surgem das suas perguntas, qual o sentido que eles atribuem ao chamado pensamento/conhecimento crítico? Do mesmo modo, não escrever da mesma forma do texto original consultado, resulta na produção de um novo texto decorrente do que Demo (1994, 2007) designa de questionamento reconstrutivo? Se isso se confirmar na prática, poder-se-ia dizer que em relação aos trabalhos de pesquisa, a prática da cópia no colégio pesquisado, identificada por Oliveira e Campello (2016) no estudo que fizeram sobre pesquisa escolar no Brasil (1989 a 2011) vem se enfraquecendo?

O mesmo não acontece em relação ao problema de pesquisa, isto é, a questão central a ser respondida pelos alunos no trabalho proposto. Segundo Oliveira e Campello (2016), a falta de questionamento por parte dos alunos, configurada nas produções que analisaram, é devido ao fato de os professores se limitarem a propor temas definidos por eles mesmos. (OLIVEIRA e CAMPELLO, 2016). O que ficou evidente na representação da maioria dos alunos do colégio considerado.

Os questionários aplicados aos alunos cumpriram de fato o nosso propósito de ampliar e aprofundar os dados que emergiram das entrevistas que com eles realizamos. Nesse sentido, a busca de dados na internet/apostilas e atribuição de nota aos trabalhos realizados aparecem reforçados, assim como, a apresentação do trabalho de pesquisa com discussão entre os alunos produz o aprofundamento crítico relativo aos temas estudados. Entre os aspectos que o questionário ofereceu como ampliação e aprofundamento das entrevistas, destacam-se a oportunidade oferecida pela pesquisa de relacionar os conteúdos das disciplinas com a realidade social, incluindo a experiência da elaboração de texto de forma mais autoral.

\section{Considerações finais}

Como se disse na introdução deste trabalho, nosso intento foi analisar as representações sociais dos alunos do Ensino Fundamental do colégio pesquisado sobre a pesquisa escolar enquanto princípio educativo. Objetivamente, buscamos

Criar Educação, Criciúma, v. 7, no2, jul/dez 2018.- PPGE - UNESC 
apreender os sentidos que vêm conseguindo construir a partir de suas experiências relativas a esta estratégia de ensino e aprendizagem.

Do processo analítico empreendido, algumas questões, que a literatura vem apontando, entre elas, a internet/livro didático como fonte de coleta de dados e atribuição de nota como objetivo precípuo da pesquisa em detrimento do aprender a pesquisar, foram confirmadas. Entretanto, o PPP do colégio ao valorizar os conhecimentos produzidos na contextualização com as experiências extraescolares dos alunos, visando a análise crítica das diferentes áreas do conhecimento, considera a pesquisa como espaço de questionamento reconstrutivo e elaboração própria (DEMO, 1994, 2007). Consideramos que a proclamação desta intenção no referido documento demonstra a disponibilidade do colégio em colocar a pesquisa como princípio educativo no lugar que defendemos neste trabalho.

Da mesma maneira, as representações sociais dos alunos expressas nas entrevistas e questionários, nos possibilitaram captar possibilidades também significativas em relação às experiências oportunizadas a eles, no campo da pesquisa escolar, como: o aprofundamento crítico relativo aos temas estudados, a oportunidade oferecida pela pesquisa de relacionar os conteúdos das disciplinas com a realidade social, incluindo a experiência da elaboração de texto de forma mais autoral.

No momento presente, no entanto, estamos sob o influxo dos questionamentos produzidos pela pesquisa - expressos neste trabalho - que nos instigam e nos motivam a continuar o diálogo com o colégio nesse sentido, agora, com os professores, apresentando as apreensões por nós obtidas e suas correspondentes interpretações, como forma de criar novos espaços de discussão e formação em relação à pesquisa escolar como princípio educativo.

\section{Referências:}

BARDIN, L. Análise de conteúdo. Lisboa: Edições 70, 2014.

BEILLEROT, J. A pesquisa: esboço de uma análise. In: ANDRÉ, M. (Org). O papel da pesquisa na formação e na prática dos professores. Campinas, SP: Papirus, 2001. p. 71-90.

CAMPELLO, B. S. OLIVEIRA, I. R. Estado da arte sobre pesquisa escolar no Brasil. Campinas: TransInformação, v. 28, n. 2, 2016. Disponível em: 
http://www.scielo.br/scielo.php?script=sci_arttext\&pid=S0103-

$37862016000200181 \&$ lng=pt\&tlng=pt

CASTORIADIS, C. Feito a ser feito: as encruzilhadas do labirinto - V. Rio de Janeiro: DP\&A, 1999.

CARDOSO, E. F. M; PEREIRA, A. S. Problematização e pesquisa no ensino fundamental: critérios e interrogações. Roteiro, Joaçaba, v: 35, n. 2, p.343-362, jul./dez. 2010.

DEMO, P. Pesquisa: princípio científico e educativo. São Paulo: Cortez, 1990.

. Pesquisa e construção de conhecimento. Rio de Janeiro: Tempo Brasileiro, 1994.

. Educar pela pesquisa. Campinas, SP: Autores Associados, 2007.

JODELET, D. Representações sociais: um domínio em expansão. In: . (Org.). As representações sociais. RJ: Eduerj, 2001. p. 17-44. Disponível em: https://pt.scribd.com/doc/61566294/Representacoes-Sociais-Cap-01-Jodelet

MOSCOVICI, S. O fenômeno das representações sociais. In:

Representações Sociais: investigações em psicologia social. Petrópolis, RJ: Vozes, 2015. p. 29-109.

Recebido em fevereiro 2018

Aprovado em julho 2018 